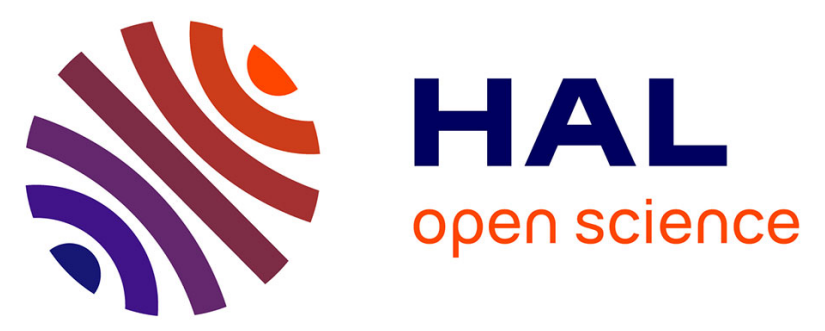

\title{
Composition of a thermal plasma formed from PTFE with copper in non-oxidant atmosphere. Part I: definition of a test case with the SF6
}

Pascal André, Zacharie Koalaga

\section{To cite this version:}

Pascal André, Zacharie Koalaga. Composition of a thermal plasma formed from PTFE with copper in non-oxidant atmosphere. Part I: definition of a test case with the SF6. High Temperature Material Processes: An International Quarterly of High-Technology Plasma Processes, 2010, 14 (3), pp.279. hal-00537752

\section{HAL Id: hal-00537752 \\ https://hal.science/hal-00537752}

Submitted on 19 Nov 2010

HAL is a multi-disciplinary open access archive for the deposit and dissemination of scientific research documents, whether they are published or not. The documents may come from teaching and research institutions in France or abroad, or from public or private research centers.
L'archive ouverte pluridisciplinaire $\mathbf{H A L}$, est destinée au dépôt et à la diffusion de documents scientifiques de niveau recherche, publiés ou non, émanant des établissements d'enseignement et de recherche français ou étrangers, des laboratoires publics ou privés. 


\title{
Composition of a thermal plasma formed from PTFE with copper in non-oxidant atmosphere. \\ Part I: definition of a test case with the $\mathrm{SF}_{6}$
}

\author{
P. ANDRE $^{1}$ and Z. KOALAGA ${ }^{2}$ \\ ${ }^{1}$ LAEPT, Blaise Pascal University, 24 av des Landais 63117 Aubiere Cedex, France \\ ${ }^{2}$ LAME, Ouagadougou University, 03 BP7021, Ouagadougou, Burkina Faso
}

\begin{abstract}
The aim of this paper is to draw the main characteristic from theoretical calculations of a good dielectric gas. The $\mathrm{SF}_{6}$ is widely used in the electrical industry for its dielectric and insulating properties. In the purpose to define available parameters, we study the molar fractions of chemical species in PTFE, $\mathrm{SF}_{6}, \mathrm{Cu}$ mixture for several proportions and pressures. We show that the carbon solid formation and condensed copper formation depends on the $\mathrm{SF}_{6}$ proportions and the presence of the electronegative ions $\mathrm{F}^{-}$.
\end{abstract}

Key Words: circuit breakers, $\mathrm{SF}_{6}, \mathrm{PTFE}$, carbon formation, copper, dielectric gas, plasma composition.

\section{Introduction}

PTFE $\left(\mathrm{C}_{2} \mathrm{~F}_{4}\right)_{\mathrm{n}}$ and sulphur Hexafluoride SF6 are widely used in industry for electrical insulating purposes and also in circuit breakers [1-5]. The $\mathrm{SF}_{6}$ gas has been well studied since a long time ago [5]. The thermodynamic properties and transport coefficients are well understood in the gas and plasma phase [6-8]. Nevertheless the molar fractions of condensed phase had not been studied in details. Notwithstanding, carbon formation on voltage breakdown and sparking is well observed since several years $[9,10]$. As a matter of fact, the main consequence of solid condensation is the failure of the breakdown. With the $\mathrm{SF}_{6}$ gas or by adding some $\mathrm{CO}_{2}$ or Halogened alkanes this carbon deposit can be partially suppressed [9, 11 ]. The dielectric gases are useful in medium and high voltage coaxial lines, in circuit breakers in substations and in transformers. At the present time the $\mathrm{SF}_{6}$ gas is usually used.

To our knowledge in the literature no available data on multiphasic composition can be found in temperatures below $6000 \mathrm{~K}$ concerning $\mathrm{SF}_{6}$ with polymer. This data can be useful to understand the creation or the cooling of the arc. Usually the contactors or the guide of the arc roots is usually constituted of copper. The arc surrounding material is made of polymer or contains it. In the working conditions the pressures can be vary from 1 bar to 30 bars $[12,13]$. That is why we choose to study the polyphasic compounds of plasma mixtures of (PTFE, $\mathrm{SF}_{6}$, $\mathrm{Cu})$.

First, we describe the data base and the computation calculation code. Secondly we describe the results obtained for three mixtures of (PTFE, SF6, Cu) respectively $(1 \%, 98 \%, 1 \%)$; $(50 \%$, $49 \%, 1 \%)$ and $(98 \%, 1 \%, 1 \%)$ in weight percentage (wp) and also we discuss the results obtained for three pressures 1 bar, 10 bars and 30 bars for the $(50 \%, 49 \%, 1 \%)$.

In conclusion and from these theoretical results, we give the conditions of a good insulating case. This conditions can be used has a definition of a case test. 


\section{Theoretical Funds}

\subsection{Physical formulation}

The computation of the chemical equilibrium of mixtures as $\left(\mathrm{SF}_{6},\left(\mathrm{C}_{2} \mathrm{~F}_{4}\right)_{\mathrm{n}}, \mathrm{Cu}\right)$ is based on the solving of equation derived from classical thermodynamics. The thermodynamic principles are valid for ideal plasma and heterogeneous plasma. Several authors use indifferently the minimization of given thermodynamic functions or mass action laws even with plasmas out of thermal equilibrium $[14,15]$. The mass action laws are never used for the heterogeneous case. In our case we consider the pressure and the temperature as fixed constraints. The thermodynamic function is the Gibbs free energy that has to be minimal if the thermodynamic system reached the thermodynamic equilibrium. So we assume the thermodynamic equilibrium for the condensed phase, the gas and the plasma. We can write this function has the sum of two terms. The first term depends on the plasma and gas phases $G_{p g}$, and the second term depends on the liquid and solid phases $G_{l s}$.

- $G_{p g}$ is written as :

$$
G_{p g}=\sum_{i=1}^{N_{p g}} n_{i}\left(\mu_{i}^{0}+R T \ln \left(\frac{n_{i}}{\sum_{j=1}^{N_{p g}} n_{j}}\right)+R T \ln \left(\frac{P}{P^{0}}\right)\right)
$$

where $n_{i}$ is the mole number,$N_{p g}$ is the number of different species present in the plasma and gas, $\mu_{i}^{0}$ is the chemical potential of $i$ species at pressure reference $P^{0}$.

- $G_{l s}$ is written as :

$$
G_{l s}=\sum_{i=1}^{N_{l s}} n_{i} \mu_{i}^{0}
$$

$N_{l s}$ is the number of liquid and solid phases taken into account for a given temperature. $\mu_{i}^{0}$ is the chemical potential of $i$ species at pressure reference $P^{0}$. The liquid is assumed to be an ideal and pure liquid that is to say there is no diffusion of the others species inside the liquid. The condensed phases (solid and liquid) are immiscible. Consequently the composition of a condensed phase follows the initial mass percentage.

\subsection{Data sources for the species thermodynamic calculation}

The pressure influence on the melting temperature of copper is low in our considered temperature range [16]. For this reason the same melting temperature for all considered pressures has been chosen fixed at $1358 \mathrm{~K}$ [17]. 
The thermodynamic properties versus temperature are taken from [17] for solid and liquid copper. The thermodynamic properties for solid carbon are those of the graphite taken from [17]. For the gaseous polyatomic species data are taken from [17]. For the monatomic and diatomic species the thermodynamic properties are calculated from the partition functions [18, 19]. The enthalpies of formation are taken in [17].

In our calculation, for the $\mathrm{SF}_{6}, \mathrm{PTFE}, \mathrm{Cu}$ mixtures, 12 monatomic species are taken into account: $\mathrm{C}, \mathrm{C}^{-}, \mathrm{C}^{+}, \mathrm{Cu}, \mathrm{Cu}^{-}, \mathrm{Cu}^{+}, \mathrm{F}, \mathrm{F}^{-}, \mathrm{F}^{+}, \mathrm{S}, \mathrm{S}^{-}, \mathrm{S}^{+}$and electrons, 20 diatomic species: $\mathrm{C}_{2}, \mathrm{C}_{2}^{-}, \mathrm{C}_{2}^{+}, \mathrm{CF}, \mathrm{CF}^{+}, \mathrm{CS}, \mathrm{CS}^{-}, \mathrm{CS}^{+}, \mathrm{Cu}_{2}, \mathrm{CuF}, \mathrm{CuS}, \mathrm{F}_{2}, \mathrm{~F}_{2}^{-}, \mathrm{F}_{2}^{+}, \mathrm{S}_{2}, \mathrm{~S}_{2}^{-}, \mathrm{S}_{2}^{+}, \mathrm{SF}, \mathrm{SF}^{-}, \mathrm{SF}^{+}$and 37 polyatomic species $\mathrm{C}_{2} \mathrm{~F}_{2}, \mathrm{C}_{2} \mathrm{~F}_{4}, \mathrm{C}_{2} \mathrm{~F}_{6}, \mathrm{C}_{3}, \mathrm{C}_{4}, \mathrm{C}_{5}, \mathrm{CF}_{2}, \mathrm{CF}_{2}^{+}, \mathrm{CF}_{3}, \mathrm{CF}_{3}^{+}, \mathrm{CF}_{4}, \mathrm{CF}_{8} \mathrm{~S}, \mathrm{CS}_{2}$, $\mathrm{CuF}_{2}, \mathrm{~F}_{10} \mathrm{~S}_{2}, \mathrm{SF}_{2}, \mathrm{SF}_{2}^{-}, \mathrm{SF}_{2}^{+}, \mathrm{SF}_{3}, \mathrm{SF}_{3}^{-}, \mathrm{SF}_{3}^{+}, \mathrm{SF}_{4}, \mathrm{SF}_{4}^{-}, \mathrm{SF}_{4}^{+}, \mathrm{SF}_{5}, \mathrm{SF}_{5}^{-}, \mathrm{SF}_{5}^{+}, \mathrm{SF}_{6}, \mathrm{SF}_{6}^{-}$, FSSF, $\mathrm{S}_{3}, \mathrm{~S}_{4}, \mathrm{~S}_{5}, \mathrm{~S}_{6}, \mathrm{~S}_{7}, \mathrm{~S}_{8}, \mathrm{SSF}_{2}$.

\section{3 numerical method}

The mole number must be non-negative and satisfy the conservation of nuclei and quasi neutrality, so the different values $n_{i}$ must satisfy both conditions:

$$
\left\{\begin{array}{l}
n_{\mathrm{i}} \geq 0 \forall i \\
\sum_{i=1}^{N_{p g}} a_{i j} n_{i}=b_{j} \quad j=0, . ., \mathrm{m}
\end{array}\right.
$$

where $m$ is the number of different nuclei. It is equal to 4 in our case $(\mathrm{C}, \mathrm{Cu}, \mathrm{F}, \mathrm{S}) . j=0$ is devoted to the electrical neutrality. $a_{i j}$ represents the nucleus number of type $j$ for particle $i$; $b_{j}$ is equal to the number of different nucleus types in the initial mixture ; $a_{i 0}$ represents the number of electric charges of type $j$ for particle $i$; so electrical neutrality imposes $b_{0}=0$. By introducing Lagrange multipliers $\pi_{k}$ to take the physical conditions (3) into account and using a Newton-Raphson numerical method a system of equation is obtained [19].

The convergence is considered to be reached when the values $\Delta n_{i}$ satisfy the following relation:

$$
\Delta n_{i}<10^{-15} n_{i} \forall i \in\left[1, N_{p g}+N_{l s}\right]
$$

In chemical equilibrium thermodynamical calculation, the main difficulty is the choice of the number of condensed (liquid and solid) species. So, the requirement for a new condensed species, which was not previously included as a possible species to now, is that its inclusion will decrease Gibbs energy. So, the test given in [20] for the two following species $\mathrm{Cu}$ (liquid and solid) and C(solid) at each step of temperature is used.

\section{3. $\mathrm{SF}_{6},\left(\mathrm{C}_{2} \mathrm{~F}_{4}\right)_{\mathrm{n}}, \mathrm{Cu}$ mixtures}

\subsection{Influence of stoichiometric parameters.}




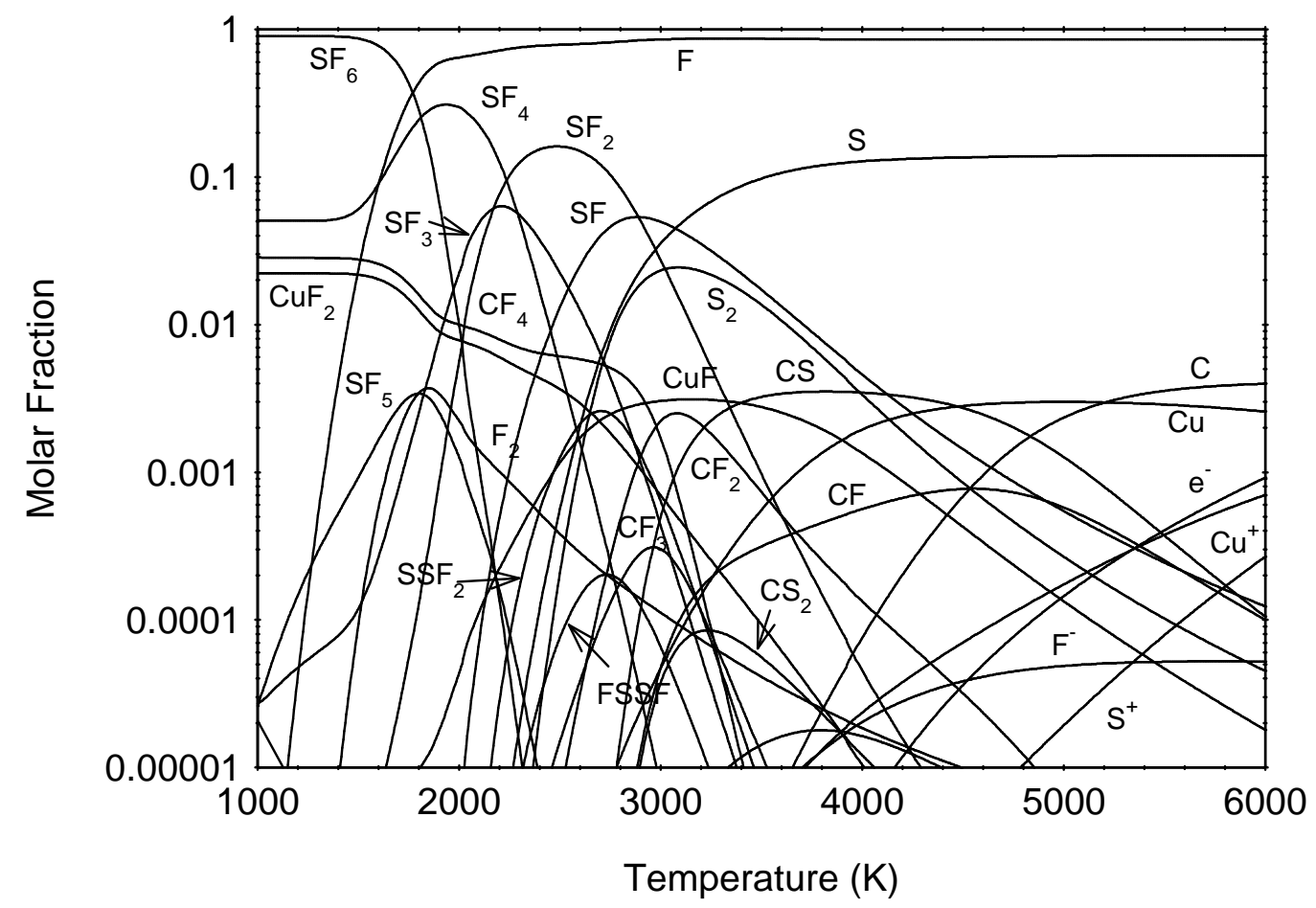

Figure 1.a: Molar fraction versus temperature at 1 bar for a mixture of $1 \%\left(\mathrm{C}_{2} \mathrm{~F}_{4}\right)_{\mathrm{n}}, 98 \% \mathrm{SF}_{6}$, $1 \% \mathrm{Cu}$ in weight percentage.

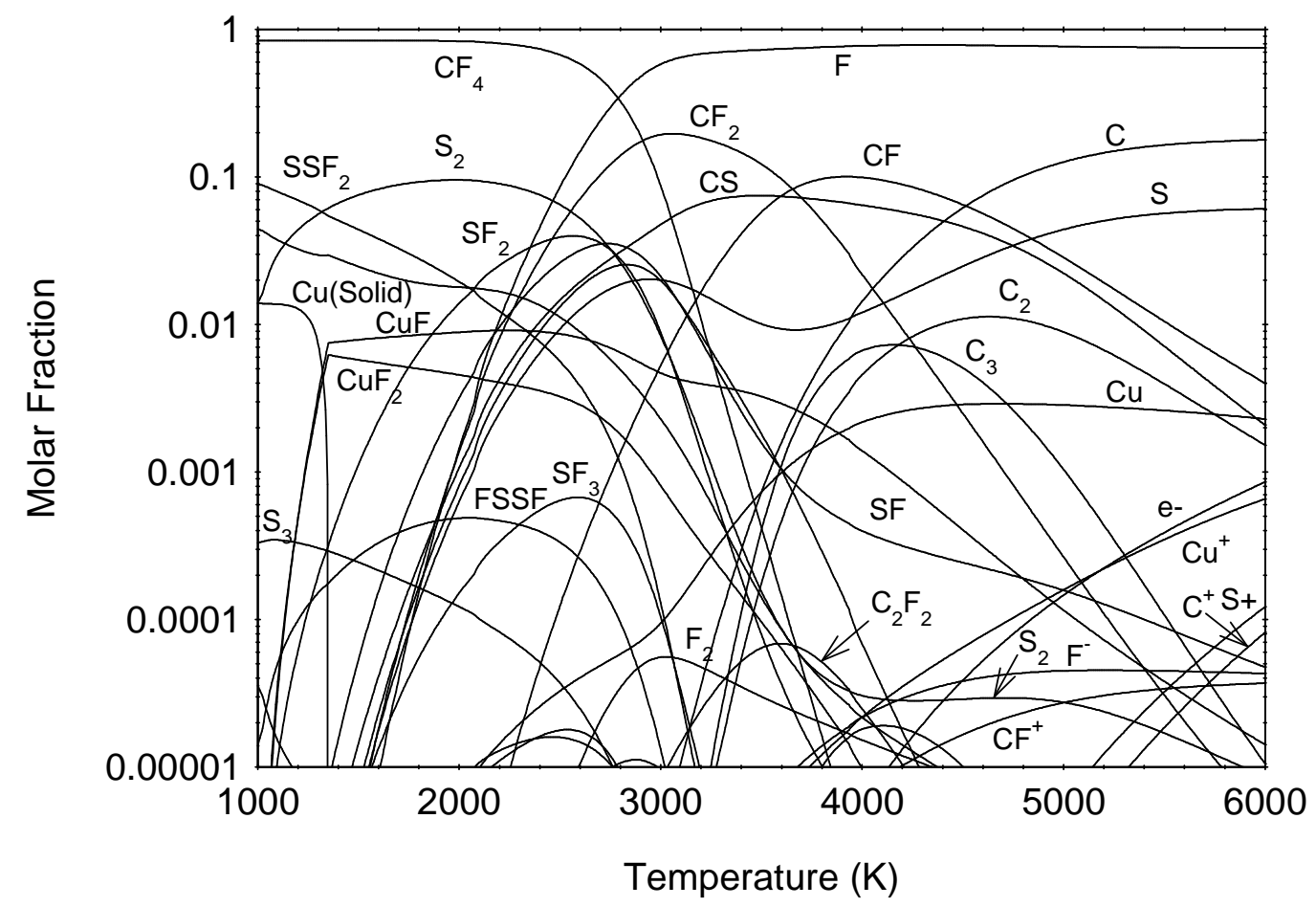

Figure 1.b: Molar fraction versus temperature at 1 bar for a mixture of $50 \%\left(\mathrm{C}_{2} \mathrm{~F}_{4}\right)_{\mathrm{n}}, 49 \%$ $\mathrm{SF}_{6}, 1 \% \mathrm{Cu}$ in weight percentage. 


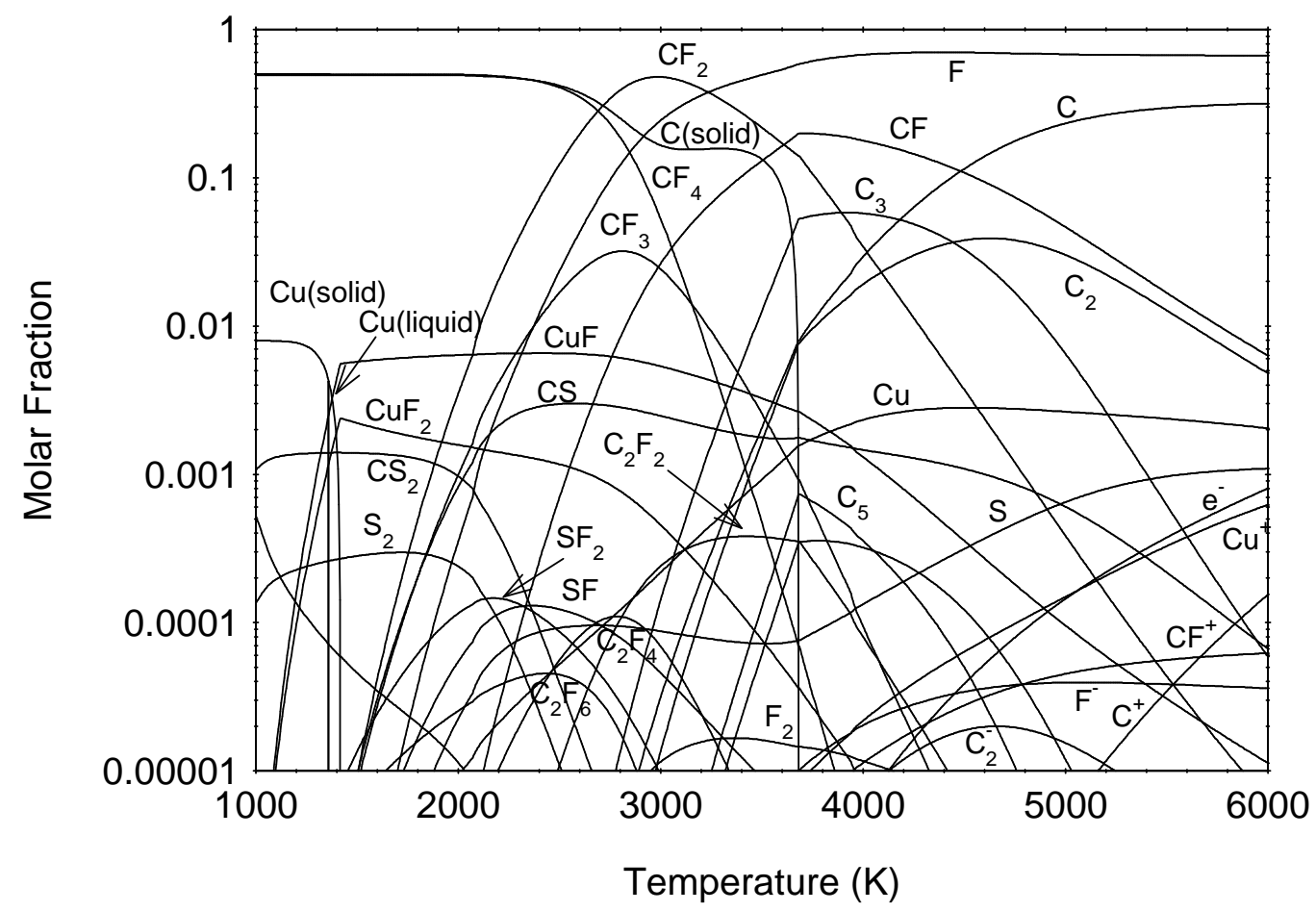

Figure 1.c: Molar fraction versus temperature at 1 bar for a mixture of $98 \%\left(\mathrm{C}_{2} \mathrm{~F}_{4}\right)_{\mathrm{n}}, 1 \% \mathrm{SF}_{6}$, $1 \% \mathrm{Cu}$ in weight percentage.

In figure 1, the molar fraction has been plotted for three mixtures based on $\mathrm{SF}_{6}, \mathrm{PTFE}$ and copper. In the case $1,1 \%\left(\mathrm{C}_{2} \mathrm{~F}_{4},\right)_{\mathrm{n}}, 98 \% \mathrm{SF}_{6}, 1 \% \mathrm{Cu}$ in weight percentage, the main chemical species are $\mathrm{SF}_{6}, \mathrm{SF}_{4}, \mathrm{CF}_{4}$ and $\mathrm{CuF}_{2}$. We do not observe any condensed phase in the considered temperature range. The $\mathrm{SF}_{6}$ molecules dissociate in $\mathrm{SF}_{4}$ and $\mathrm{F}$ at temperature around $1800 \mathrm{~K} . \mathrm{SF}_{4}$ molecules dissociate in $\mathrm{SF}_{2}$ and $\mathrm{F}$ at a temperature around $2240 \mathrm{~K}$ and $\mathrm{SF}_{2}$ molecule dissociate in SF and F around a temperature of $3000 \mathrm{~K}$. Around $3080 \mathrm{~K}$ the diatomic molecules SF dissociate in S and F. For the higher temperature $6000 \mathrm{~K}$ the main chemical species are monatomic $\mathrm{F}, \mathrm{S}, \mathrm{C}$ and $\mathrm{Cu}$ that the basic elements of the mixture. For the charged particles, the electrical neutrality is reached between $\mathrm{Cu}^{+}$and $\mathrm{F}^{-}$for the temperature lower than $4500 \mathrm{~K}$ and $\mathrm{e}^{-}$and $\mathrm{Cu}^{+}$for the higher temperature in the considered temperature range.

In the case $2,50 \%\left(\mathrm{C}_{2} \mathrm{~F}_{4}\right)_{\mathrm{n}} 49 \% \mathrm{SF}_{6} 1 \% \mathrm{Cu}$, the main chemical species are $\mathrm{CF}_{4}, \mathrm{SSF}_{2}, \mathrm{~S}_{2}$ and solid copper. The $\mathrm{CF}_{4}$ molecules dissociate in $\mathrm{CF}_{2}$ and $\mathrm{F}$ at a temperature around $2900 \mathrm{~K}$. $\mathrm{CF}_{2}$ molecules dissociate in $\mathrm{CF}$ and $\mathrm{F}$ around $3650 \mathrm{~K}$ and $\mathrm{CF}$ dissociates in $\mathrm{C}$ and $\mathrm{F}$ around 4500 $\mathrm{K}$. The solid copper sublimates in $\mathrm{CuF}$ and $\mathrm{CuF}_{2}$ at a temperature of $1350 \mathrm{~K}$. For the higher temperature at $6000 \mathrm{~K}$ the main chemical species are $\mathrm{F}, \mathrm{S}, \mathrm{C}, \mathrm{CF}, \mathrm{CS}, \mathrm{Cu}$ and $\mathrm{C}_{2}$. The electrical neutrality is reach between $\mathrm{Cu}^{+}$and $\mathrm{F}^{-}$for the temperature lower than $4500 \mathrm{~K}$ and $\mathrm{e}^{-}$ and $\mathrm{Cu}^{+}$for the higher temperature in the considered temperature range.

In the case $3,98 \%\left(\mathrm{C}_{2} \mathrm{~F}_{4},\right)_{\mathrm{n}} 1 \% \mathrm{SF}_{6} 1 \% \mathrm{Cu}$, the main chemical species are solid carbon, $\mathrm{CF}_{4}$, and solid copper at low temperature. The $\mathrm{CF}_{4}$ molecules dissociate in $\mathrm{CF}_{2}$ and $\mathrm{F}$ at a temperature around $2690 \mathrm{~K} . \mathrm{CF}_{2}$ molecules dissociate in solid carbon and $\mathrm{F}$ between $3050 \mathrm{~K}$ and $3700 \mathrm{~K}$. Thus the molar fraction of solid carbon is stable in this temperature range. At $3685 \mathrm{~K}$, when solid carbon sublimates in $\mathrm{CF}$ and $\mathrm{C}_{3}$, the $\mathrm{CF}_{2}$ molecules dissociate in $\mathrm{CF}$ and F. Around $4480 \mathrm{~K}, \mathrm{CF}$ dissociates in $\mathrm{C}$ and $\mathrm{F}$. The liquid phase of copper vaporizes at $1418 \mathrm{~K}$ 
in $\mathrm{CuF}$ and $\mathrm{CuF}_{2}$. For the higher temperature $6000 \mathrm{~K}$ the species are monatomic $\mathrm{F}, \mathrm{C}, \mathrm{CF}, \mathrm{C}_{2}$ and $\mathrm{Cu}$. The electrical neutrality is reach between $\mathrm{Cu}^{+}$and $\mathrm{F}^{-}$for the temperature lower than $4500 \mathrm{~K}$ and $\mathrm{e}^{-}$and $\mathrm{Cu}^{+}$for the higher temperature in the considered temperature range.

Comparing the three considered cases, the role of stoichiometric coefficients are indubitable. The chemical compounds are different and depends on the proportion of $\mathrm{SF}_{6}$ and $\left(\mathrm{C}_{2} \mathrm{~F}_{4},\right)_{\mathrm{n}}$. The higher the proportion of $\mathrm{SF}_{6}$ the lower the proportion of solid carbon. We also notice the $\mathrm{CF}_{4}$ molecules that are present in each considered cases. The neutrality in gas phase is made at low temperature between $\mathrm{F}^{-}$and $\mathrm{Cu}^{+}$. In figure 2, we present the evolution of the solid carbon and the condensed copper for several proportions of $\mathrm{SF}_{6}$ and PTFE. For the high proportion of $\mathrm{SF}_{6}(>50 \%$ in wp) the solid and liquid phases of copper and solid phase of solid carbon disappear in the considered temperature range.

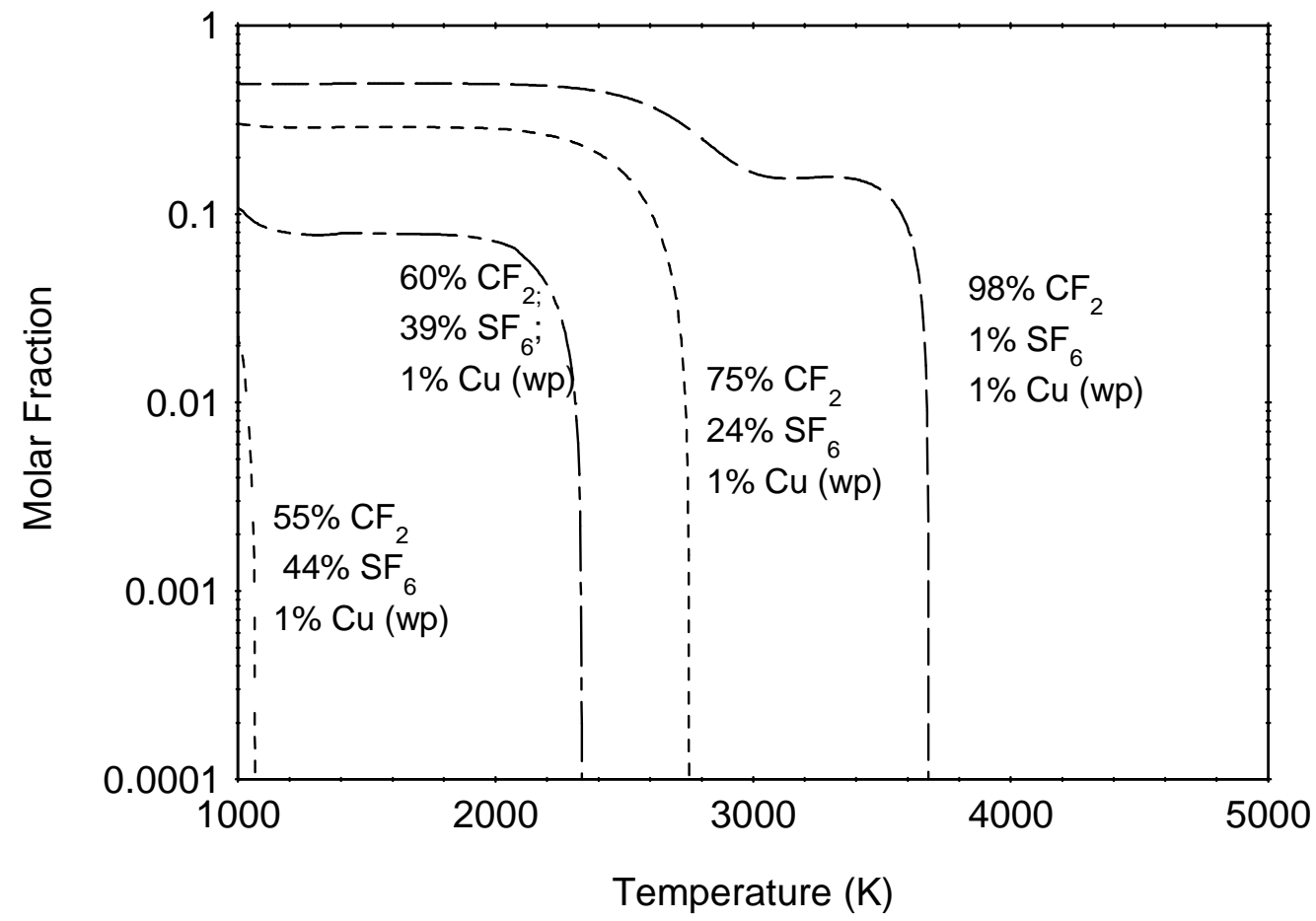

Figure 2.a.: Evolution of solid carbon formation molar fraction versus temperature and for several proportion of $\mathrm{SF}_{6},\left(\mathrm{C}_{2} \mathrm{~F}_{4}\right)_{\mathrm{n}}$ and $\mathrm{Cu}$. 


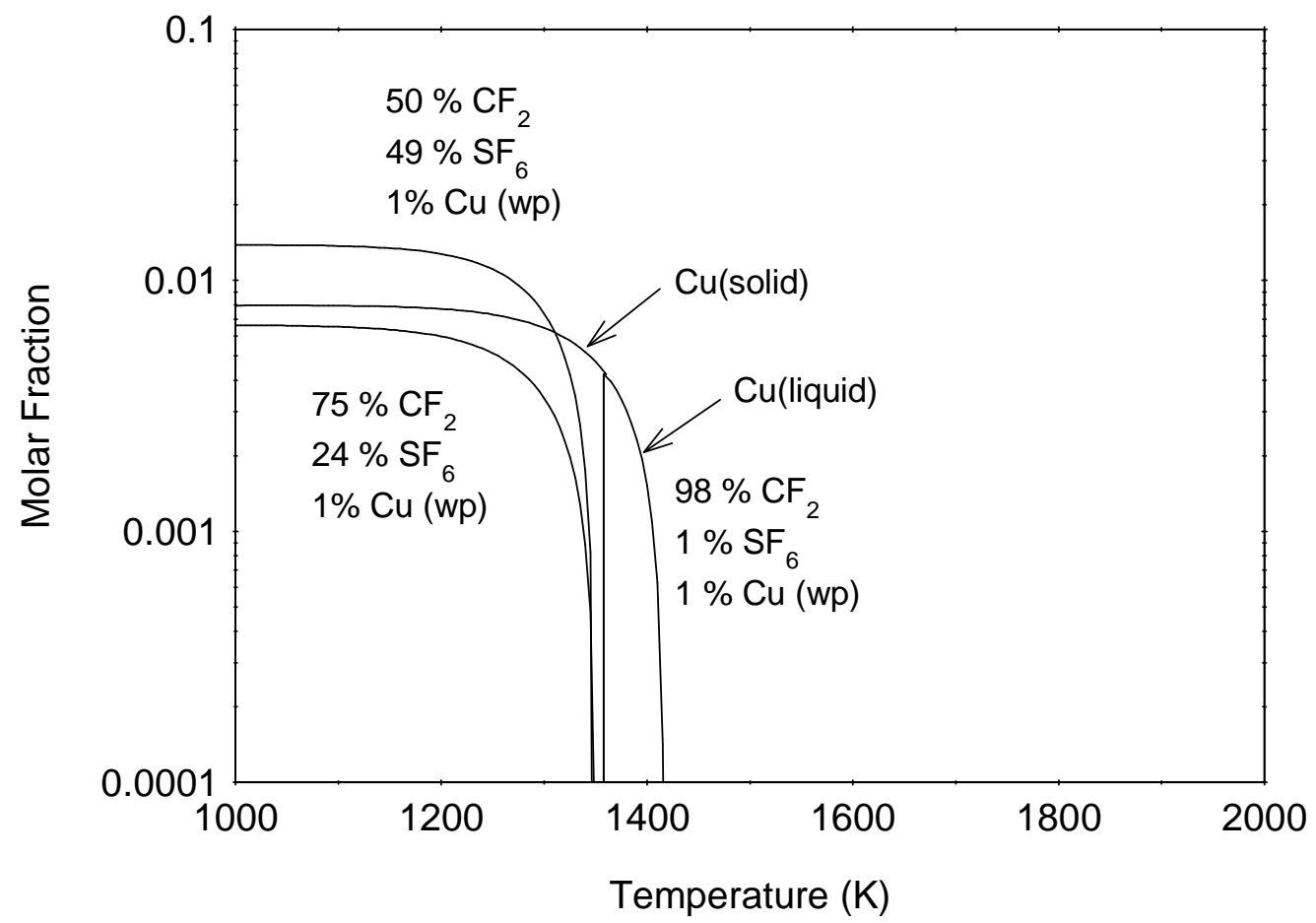

Figure 2.b.: Evolution of copper molar fraction versus temperature and for several proportions of $\mathrm{SF}_{6},\left(\mathrm{C}_{2} \mathrm{~F}_{4}\right)_{\mathrm{n}}$ and $\mathrm{Cu}$.

\subsection{Influence of the pressure}

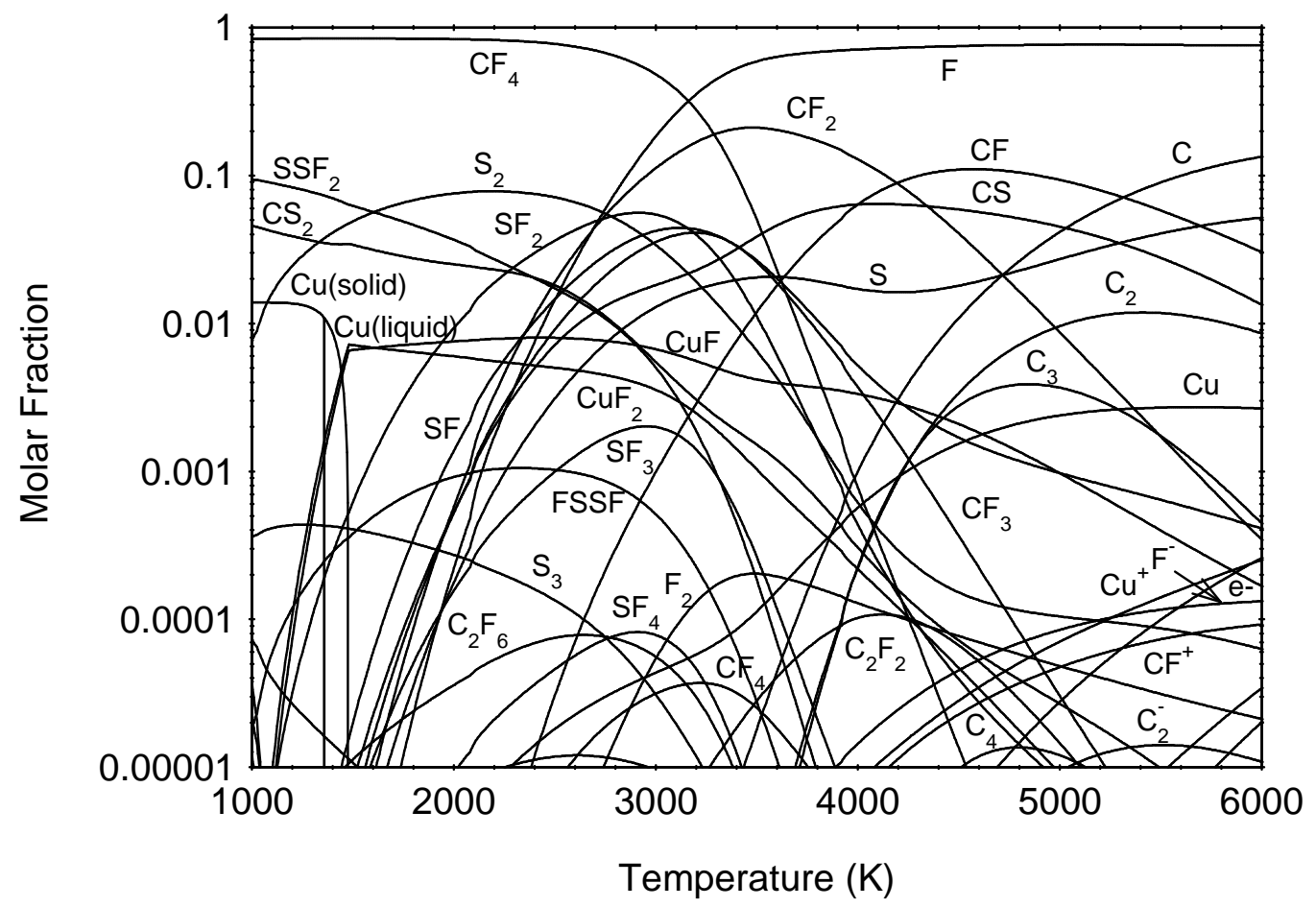

Figure 3.a: Molar fraction versus temperature at 10 bars for a mixture of $50 \%\left(\mathrm{C}_{2} \mathrm{~F}_{4}\right)_{\mathrm{n}}, 49 \%$ $\mathrm{SF}_{6}, 1 \% \mathrm{Cu}$ in weight percentage. 


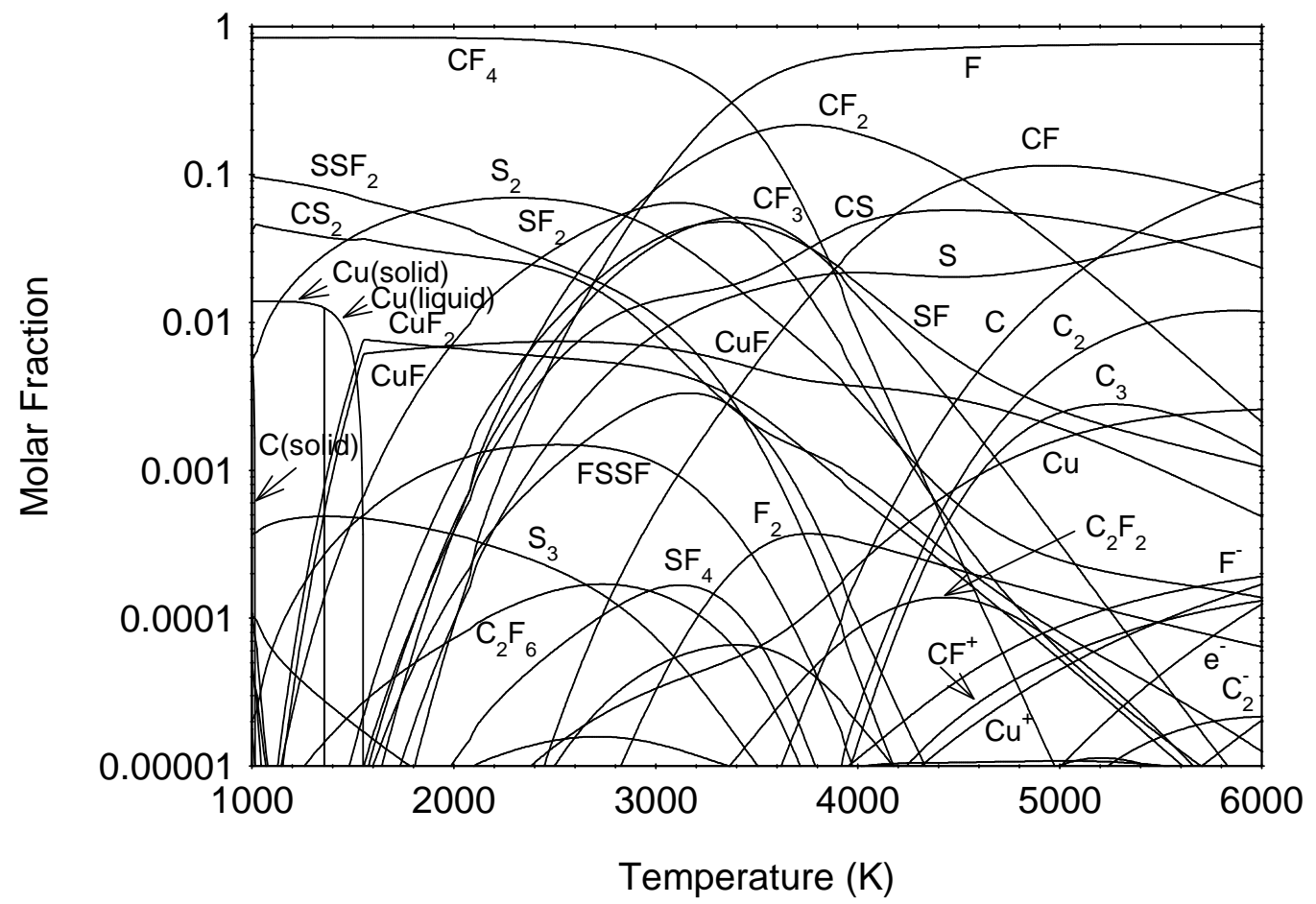

Figure 3.b: Molar fraction versus temperature at 30 bars for a mixture of $50 \%\left(\mathrm{C}_{2} \mathrm{~F}_{4}\right)_{\mathrm{n}}, 49 \%$ $\mathrm{SF}_{6}, 1 \% \mathrm{Cu}$ in weight percentage.

In figure 3 , in the case of $50 \%\left(\mathrm{C}_{2} \mathrm{~F}_{4}\right)_{\mathrm{n}}, 49 \% \mathrm{SF}_{6}, 1 \% \mathrm{Cu}$ in weight percentage for two pressures 10 bars and 30 bars, the molar fraction are plotted versus the temperature. The dissociation of $\mathrm{CF}_{4}$ in $\mathrm{CF}_{2}$ and $\mathrm{F}$ is made at $2900 \mathrm{~K}$ at 1 bar, $3160 \mathrm{~K}$ at 10 bars and $3500 \mathrm{~K}$ at 30 bars. $\mathrm{CF}_{2}$ dissociates in $\mathrm{CF}$ and $\mathrm{F}$ around $3650 \mathrm{~K}$ at 1 bar, $4200 \mathrm{~K}$ at 10 bars and $4525 \mathrm{~K}$ at 30 bars. CF dissociates in $\mathrm{C}$ and $\mathrm{F}$ around $4500 \mathrm{~K}$ at 1 bar, $5300 \mathrm{~K}$ at 10 bars and $5800 \mathrm{~K}$ at 30 bars. The solid copper sublimates in $\mathrm{CuF}$ and $\mathrm{CuF}_{2}$ at a temperature of $1350 \mathrm{~K}$ at 1 bar, 1480 $\mathrm{K}$ at 10 bars and $1550 \mathrm{~K}$. The solid carbon appears at low temperature and sublimates at 1015 $\mathrm{K}$ for a pressure of 30 bars. For the higher temperature $6000 \mathrm{~K}$, we observe the higher pressure the higher molecule molar fractions. So the main species for $6000 \mathrm{~K}$ at 1 bar are F, S, $\mathrm{C}, \mathrm{CF}, \mathrm{CS}, \mathrm{Cu}$ and $\mathrm{C}_{2}$ and for 30 bars $\mathrm{F}, \mathrm{C}, \mathrm{CF}, \mathrm{S}, \mathrm{CS}, \mathrm{C}_{2}, \mathrm{CF}_{2}$ and $\mathrm{C}_{3}$. The electrical neutrality is reach between $\mathrm{Cu}^{+}$and $\mathrm{F}^{-}$for the temperature lower than $4500 \mathrm{~K}$ and $\mathrm{e}^{-}$and $\mathrm{Cu}^{+}$ for the higher temperature in the considered temperature range at 1 bar. For 10 bars, the electrical neutrality is reach between $\mathrm{Cu}^{+}$and $\mathrm{F}^{-}$for the temperature lower than $5260 \mathrm{~K}$ and $\mathrm{e}^{-}$ and $\mathrm{Cu}^{+}$for the higher temperature. For 30 bars, the electrical neutrality is made between $\mathrm{F}^{-}$, $\mathrm{CF}^{+}$and $\mathrm{Cu}^{+}$. 


\section{Conclusion}

In this paper, we have presented the molar fraction of mixture of PTFE, $\mathrm{SF}_{6}$ and copper for several proportions and pressures versus the temperature. The $\mathrm{SF}_{6}$ is remarkable since it has different behaviour versus its proportions in the mixture. As a matter of fact we have shown that the chemical composition and the presence of non electrical conducting species at low temperature in the mixture depend on the proportion of the $\mathrm{SF}_{6}$. Furthermore, we have shown that the solid carbon formation and condensed copper disappears when a high proportion of $\mathrm{SF}_{6}$ is present in the plasma. So to test the efficiency of a dielectric gas, we have to study the solid carbon formation and condensed copper. Furthermore, the presence of the electronegative ions $\mathrm{F}^{-}$helps to avoid the re-strike of the arc. As a mater of fact, the mobility of ions is lower than electrons. The presence of electronegative species in a good proportion is also required to avoid re-strike of the arc.

\section{References}

[1] Chu, F. Y. SF6 Decomposition in Gas-Insulated Equipment IEEE Transactions on Electrical Insulation Issue: 5, Vol EI-21, p 693-725, 1986.

[2] Qui, Y. Sun, A. Kuffel, E. Improved Dielectric Strength of SF6 Gas with a Trichlorotrifluoroethane Vapor Additive Issue: 6, Vol EI-22, p 763-768, 1987.

[3] Pham,V. D., Thuries E., Martin J. Patent EP19910117923, 12/20/1995.

[4] Fleischer L., Müller H.J., Poth R., Späck H. Patent EP19950940161, 09/30/1998.

[5] Chritophorou L.G., Olthoff J.K., Van Brunt RJ Van Sulfur Hexafluoride and the Electric Power Industry IEEE Electrical Insulation Magazine Vol 13, N5 p 20-24, 1997.

[6] Chervy B, Gleizes A, Razafinimanana M, Thermodynamic properties and transport coefficients in SF6-Cu mixtures at temperatures of 300-30 000K and pressures of 1.-1MPa, J.Phys D: Appl. Phys., Vol 27, p 1193-1206, 1994.

[7] Krenek P., Thermophysical properties of the reacting mixture SF6 and $\mathrm{Cu}$ in the range 3000 to $50000 \mathrm{~K}$ and 0.1 t $2 \mathrm{MPa}$, Acta Techn CSAV, Vol 37, p 399-410, 1992.

[8] Belov V A, Semenov AM Calculation of the thermal conductivity of a sulfur hexafluorides plasma in the range $10^{3}<T<2010^{3}$ at pressures of $1,2,5$ and 10 atm.

Teplofizika Vysokikh Temperatur, Vol 9, N², p282-289, 1971.

[9] Mears W.H., Sabatino R.O., US Patent 4071461, 1978.

[10] Hayashi Y, Okino A, Hotta E, Uchii T, Cliteur G, Suzuki K, Observation of weakly Ionized Dusty Plasma in Exhaust gas in a compact size SF6 gas circuit breaker, IEEE Transactions on plasma science, Vol 29, N¹, p 99-101, 2001.

[11] Manion JP, Philosophos JA, Robinson MB, US Patent 3650955, 1972

[12] Boveri B Theoretical description of the current interruption in HV gas blast breakers, IEEE Transactions on Power Apparatus and systems, Vol PAS 96, №5, p1546-1555, 1977.

[13] Shiminn DW, Jones GR, Ali SMG, Transient pressure variations in SF6 puffer circuit breakers, J. Phys D: Appl. Phys., Vol 23, p 533-541, 1990.

[14] Tanaka Y. Particle composition of high pressure SF6 plasma with electron temperature greater than gas temperature IEEE Transactions on plasma science, Vol 25, N5, p 991-995, 1997.

[15] Andre P, Etude d'un plasma de SF 6 hors d'équilibre thermique, (in French), J. Phys. III, Vol 7, p 1339-1359 1997.

[16] Bridgman P.W. The Physics of high pressure, G. Bell and Sons editors, London, 1949. 
[17] JANAF, Thermochemical tables, $4^{\text {th }}$ edn, MW Chases (ed.), J Phys. Chem. Ref Data, $\mathrm{N}^{\circ} 9,1998$.

[18] André P. Partition functions and concentrations in plasmas out of thermal equilibrium IEEE Transactions on Plasma Science, Vol 23, issue 3, p 453-458, 1995.

[19] Rochette D., Bussière W., André P., Composition, Enthalpy, and Vaporization Temperature Calculation of $\mathrm{Ag}-\mathrm{SiO}_{2}$ Plasmas with Air in the Temperature Range from 1000 to $6000 \mathrm{~K}$ and for Pressure Included between 1 and 50 bars, Plasma Chemistry and Plasma Processing, Vol 24, N³, p 475-492, 2004.

[20] Gordon and McBride, Computer Program for Calculation of Complex Chemical Equilibrium Compositions, Rocket Performance, Incident and Reflected Shocks, and Chapman-Jouguet Detonations, NASA SP-273, 1976

\section{Acknowledgments:}

The authors wish to thank the European Edulink Program for their financial support to help the development of scientific cooperation between Blaise Pascal University and University of Ouagadougou, and the two laboratories LAME and LAEPT. 